\title{
The Epidemiology, Risk Profiling and Diagnostic Challenges of Nonalcoholic Fatty Liver Disease
}

\author{
Umair Iqbal ${ }^{1, *}$, Brandon J. Perumpail ${ }^{2}$, Daud Akhtar ${ }^{3}$, Donghee Kim ${ }^{4}\left([)\right.$ and Aijaz Ahmed ${ }^{4}(\mathbb{C}$ \\ 1 Department of Medicine, Geisinger Commonwealth School of Medicine, Danville, PA 17822, USA \\ 2 Department of Medicine, Drexel University College of Medicine, Philadelphia, PA 19129, USA; \\ brandonperumpail@gmail.com \\ 3 Department of Medicine, University of British Columbia, Vancouver, BC V6T 1Z4, Canada; \\ dakhtar@alumni.ubc.ca \\ 4 Division of Gastroenterology and Hepatology, Stanford University School of Medicine, Stanford, CA 94305, \\ USA; dhkimmd@stanford.edu (D.K.); aijazahmed@stanford.edu (A.A.) \\ * Correspondence: uiqbal@geisinger.edu or umairiqbal_dmc@hotmail.com
}

Received: 18 February 2019; Accepted: 9 March 2019; Published: 18 March 2019

\begin{abstract}
Nonalcoholic fatty liver disease (NAFLD) encompasses a wide spectrum of liver damage from the more prevalent $(75 \%-80 \%)$ and nonprogressive nonalcoholic fatty liver (NAFL) category to its less common and more ominous subset, nonalcoholic steatohepatitis (NASH). NAFLD is now the most common cause of chronic liver disease in the developed world and is a leading indication for liver transplantation in United States (US). The global prevalence of NAFLD is estimated to be $25 \%$, with the lowest prevalence in Africa (13.5\%) and highest in the Middle East (31.8\%) and South America (30.4\%). The increasing incidence of NAFLD has been associated with the global obesity epidemic and manifestation of metabolic complications, including hypertension, diabetes, and dyslipidemia. The rapidly rising healthcare and economic burdens of NAFLD warrant institution of preventative and treatment measures in the high-risk sub-populations in an effort to reduce the morbidity and mortality associated with NAFLD. Genetic, demographic, clinical, and environmental factors may play a role in the pathogenesis of NAFLD. While NAFLD has been linked with various genetic variants, including PNPLA-3, TM6SF2, and FDFT1, environmental factors may predispose individuals to NAFLD as well. NAFLD is more common in older age groups and in men. With regards to ethnicity, in the US, Hispanics have the highest prevalence of NAFLD, followed by Caucasians and then African-Americans. NAFLD is frequently associated with the components of metabolic syndrome, such as type 2 diabetes mellitus (T2DM), obesity, hypertension, and dyslipidemia. Several studies have shown that the adoption of a healthy lifestyle, weight loss, and pro-active management of individual components of metabolic syndrome can help to prevent, retard or reverse NAFLD-related liver damage. Independently, NAFLD increases the risk of premature cardiovascular disease and associated mortality. For this reason, a case can be made for screening of NAFLD to facilitate early diagnosis and to prevent the hepatic and extra-hepatic complications in high risk sub-populations with morbid obesity, diabetes, and other metabolic risk factors.
\end{abstract}

Keywords: nonalcoholic fatty liver disease; nonalcoholic steatohepatitis; NAFLD; NASH; liver biopsy

\section{Introduction}

Nonalcoholic fatty liver disease (NAFLD) is the most common cause of chronic liver disease in the developed world and is one of the leading indications for liver transplantation in the United States (US) [1,2]. Over 64 million people in the US are estimated to have NAFLD, with annual medical costs of approximately $\$ 103$ billion (1612.18 per patient) [3]. NAFLD comprises nonalcoholic fatty 
liver (NAFL), which is characterized by the presence of hepatic steatosis without the presence of any substantial inflammation, and nonalcoholic steatohepatitis (NASH), which is defined by the histologic presence of hepatic steatosis with lobular inflammation, and hepatocellular balloon degeneration with and without pericellular fibrosis [3]. The components of metabolic syndrome have been associated with the pathogenesis of NAFLD. These include risk factors such as obesity, diabetes, hypertension, and dyslipidemia [2]. Additionally, the pathogenesis of NAFLD also comprises genetic, demographic, clinical, and environmental factors that all play a role in determining the likelihood of NAFLD. Despite the NAFLD epidemic in chronic liver disease, direct treatment options are still lacking and thus add to the economic burden on healthcare systems [3]. For this reason, there is a need to identify the risk factors associated with NAFLD to effectively screen patients. The purpose of this article is to discuss the epidemiologic trends, risk factors, and the current modalities involved in the diagnostic evaluation of NAFLD.

\section{Epidemiology of NAFLD}

\subsection{Prevalence and Distribution of NAFLD}

The worldwide increase in the prevalence of well-established risk factors for NAFLD, such as diabetes, obesity, and age, has had an accompanying increase in the prevalence of NAFLD. The global prevalence of NAFLD is estimated to be around 25\% [4]. In a recent meta-analysis, NAFLD was found to be most prevalent in the Middle East (31.8\%), followed by South America (30.4\%). NAFLD was also found to be least prevalent in Africa (13.5\%) [4]. Comparatively, the prevalence of NAFLD in Asia, Europe, and North America was found to be $27.4 \%, 23.7 \%$, and $24.1 \%$ respectively [4]. Figure 1 summarizes the prevalence of NAFLD across the world. The US population has seen a similar trend with the National Health and Nutrition Examination Survey (NHANES), demonstrating a doubling in the prevalence of NAFLD in the US from 5.5\% (1988-1994) to 11\% (2005-2008) [1]. In a study using the fatty liver index to diagnose NAFLD, the prevalence of NAFLD increased from 18\% in 1988-1991 to $31 \%$ in 2011-2012 [5]. Concerningly, the prevalence of NASH in the general population is estimated to range between $1.5 \%$ and $6.4 \%$ [4]. This increasing prevalence of NAFLD in the US parallels the increase in prevalence of NAFLD-related risk factors, which include insulin resistance, obesity, hypertension, and dyslipidemia.

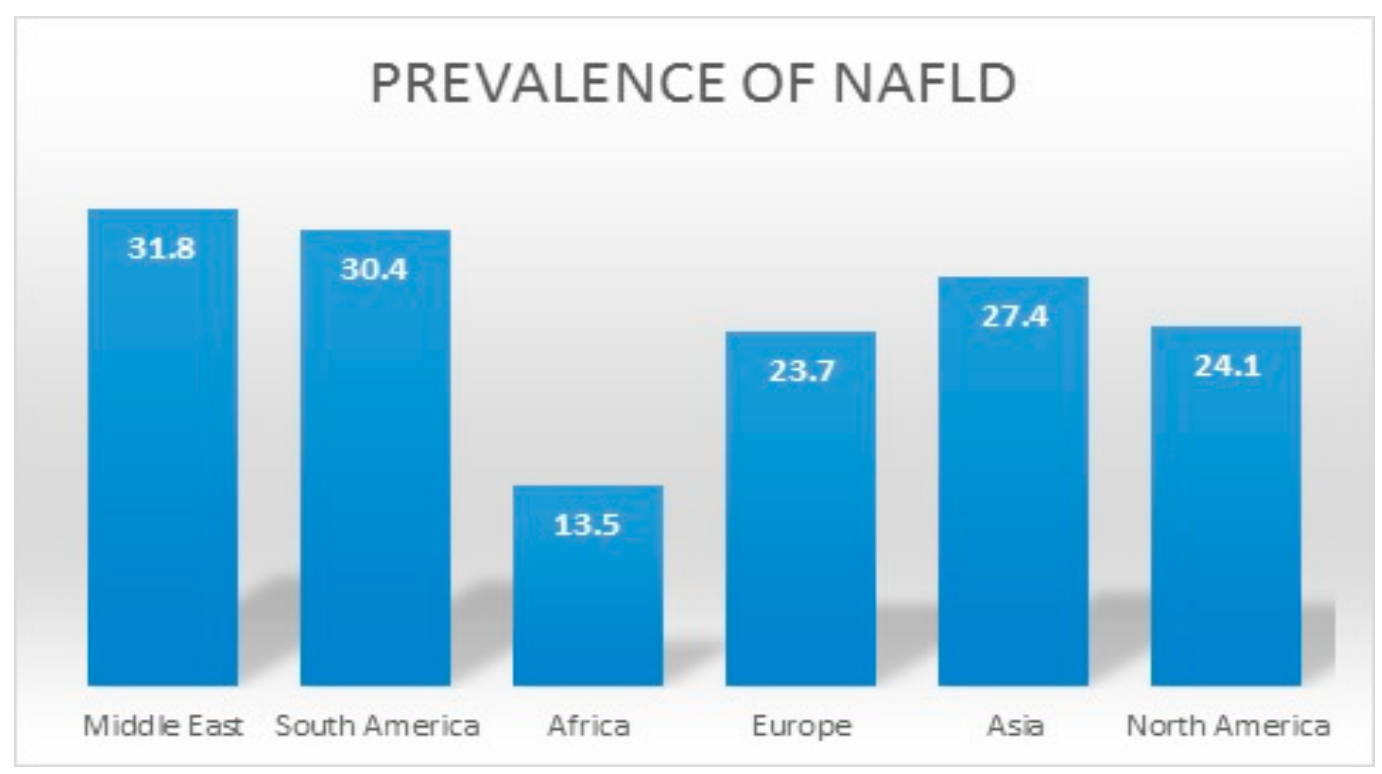

Figure 1. Prevalence of nonalcoholic fatty liver disease (NAFLD) across the world [4]. 


\subsection{Populations with NAFLD}

Diabetes and obesity, in particular, are significant health concerns that are heavily associated with NAFLD. A recent systematic review estimated the global prevalence of NAFLD in diabetic patients to be around 58\% [6]. Specifically, the prevalence of NASH in diabetic patients has been demonstrated to be close to $65 \%[6,7]$. Furthermore, NAFLD is also highly prevalent in the overweight and obese population. The prevalence of NAFLD in morbidly obese patients who undergo bariatric surgery has been reported to be as high as 95\% [8]. Although there is a strong association between NAFLD and excess body weight, NAFLD can also present in patients with a normal body mass index (BMI). Approximately $5-10 \%$ of NAFLD patients in the US are within the normal limits for BMI and are commonly referred to as having lean NAFLD [9]. The pathogenesis of lean NAFLD is analogous to that of obese NAFLD and is similarly accompanied by excessive abdominal fat, diabetes, and hypertension. Age is another important consideration with regard to NAFLD. NAFLD is more prevalent in older patients, with the majority of patients being diagnosed between 40 to 50 years of age. The risk of NASH and fibrosis also increases with age. The prevalence of NAFLD also varies with gender and ethnicity, with there being a greater prevalence in males and individuals of Hispanic descent [4]. Yang et al. displayed that men are at a higher risk of severe fibrosis when compared to premenopausal females. The risk, however, is similar in post-menopausal females, suggesting that female hormones may have protective effects on hepatic fibrosis [10]. A remodeling study by Estes et al. estimated that the prevalence of NAFLD and NASH in the US will rise by $21 \%$ and $63 \%$, respectively, with a correlated increase of $178 \%$ in liver-related mortalities to an estimated 78,300 deaths by 2030 . For this reason, there is a critical need to identify and treat potentially modifiable risk factors in order to reduce the morbidity and mortality associated with this serious disease [11].

\section{Risk Profiling for NAFLD}

\subsection{Genetic Predisposition to NAFLD}

Although obesity, metabolic syndrome, and insulin resistance are the most prevalent risk factors that lead to the development of NAFLD, NAFLD varies substantially among subjects with comparable lifestyles, environmental exposures, and metabolic abnormalities. This suggests that other factors do contribute to the pathogenesis of NAFLD, with genetic predisposition possibly being an important factor. Several epidemiological, familial, and twin studies have shown possible familial predispositions for NAFLD. Struben et al. demonstrated in a study of eighteen members the coexistence of histologically proven NASH and cirrhosis among multiple generations of kindreds [12]. A family study of 157 individuals with familial combined hyperlipidemia revealed an increased prevalence of fatty liver and elevated levels of ALT in both dyslipidemic patients and family members with normal lipid levels [13]. Loomba et al. further revealed a strong association between serum GGT levels, fatty liver, and beta-2-adrenergic receptors in identical twins [14]. NAFLD has been shown to cluster in families with certain genetic variants. These include TM6SF2, PNPLA3, NCAN, and PPP1R3B genes that increase the heritability of NAFLD to up to $27 \%$ [15-21]. One genetic variant linked with NAFLD is a missense mutation [Ile148->Met148 (I148M)] in the Palatin-like phospholipase domain-containing 3 gene (PNPLA3) [9]. PNPLA3 exerts a strong influence on hepatic fat accumulation in GG homozygous individuals, showing 73\% more hepatic fat content when compared with CC homozygous individuals. These patients were also more susceptible to the development of more severe histologic liver damage, with a 3.24-fold greater risk of higher necro-inflammatory scores and a 3.2-fold greater risk of developing fibrosis [15]. These associations were maintained irrespective of the degree of obesity or the presence of diabetes $[16,17]$. The single variant in the PNPLA3 gene (I148M) has been shown to occur with the greatest frequency in Hispanics, followed by non-Hispanic whites, and the least in African Americans [9]. This may explain the low prevalence of NAFLD in African Americans despite the higher prevalence of obesity and diabetes in this population [4]. A minor allele in transmembrane 5 superfamily member 2 (TM6SF2) was associated with magnetic resonance 
spectroscopy-measured hepatic triglyceride content from the Dallas Heart Study [20]. In addition, the minor allele of TM6SF2 was noted to increase the risk for hepatic fibrosis independent of age, obesity, diabetes, and PNPLA3 genotype [21]. Other genetic variants, such as Farnesyl diphosphate farnesyl transferase I (FDFT1), Collage type XIII, alpha 1 (COL13A1), and neurocan (NCAN), which have been identified by genomewide scans, have also been implicated with increased susceptibility to NAFLD [19]. Table 1 summarizes these different genetic variants linked with NAFLD.

Table 1. Genetic variants associated with NAFLD.

\begin{tabular}{ll}
\hline Gene & Effect on NAFLD/NASH \\
\hline $\begin{array}{l}\text { Palatine like phospholipase domain containing 3 } \\
\text { (PNPLA-3) [15-17] }\end{array}$ & $\begin{array}{l}\text { Increased risk of hepatic steatosis, incidence of NASH } \\
\text { and severity of fibrosis }\end{array}$ \\
\hline Farnesyl diphosphate farnesyl transferase I (FDFT1) [19] & Increased severity of NAFLD activity score \\
\hline Collagen type XIII alpha 1 (COL13A1) [19] & Increased severity of fibrosis \\
\hline Neurocan (NCAN) [19] & Increased risk hepatic steatosis \\
\hline Glucokinase regulatory protein (GCKR) [19] & Increased risk hepatic steatosis \\
\hline Transmembrane 5 superfamily member 2 (TM6SF2) [21] & Increased risk for hepatic fibrosis \\
\hline
\end{tabular}

\subsection{Gender and Age-Related Risk for NAFLD}

Gender and age are important considerations with regards to NAFLD. The prevalence of NAFLD and NASH is generally higher in men [22-25]. However, some studies have also reported a higher prevalence of NAFLD in women [26,27]. In men, NAFLD follows an "Inverted U-Shaped Curve" with the prevalence increasing from younger to middle-aged individuals and then decreasing around the age of 50 [23-25]. The prevalence of NAFLD appears to be lower in premenopausal women and increases significantly after the age of 50, ultimately, peaking in the 6th decade of life [23-25]. Yang et al. displayed that men are at a higher risk of severe fibrosis when compared to premenopausal women. The risk, however, is similar in post-menopausal women, suggesting that female hormones may have protective effects on hepatic fibrosis [10]. NAFLD is more prevalent with advanced age due to an increase in the prevalence of NAFLD-related risk factors, such as metabolic syndrome, diabetes, and hypertension. The risk of fibrosis and NASH also increases with advancing age. A recent systematic review demonstrated that advancing age was found to be an independent predictor of advanced fibrosis [28]. Advancing age also increases the extrahepatic manifestations of NAFLD and, thus, there is an increased risk for morbidity and mortality in older populations. The effects of gender on the outcomes of NAFLD is still unclear, although some studies have reported worse outcomes of NAFLD in men [29,30].

\subsection{Differences in NAFLD from Race/Ethnicity}

Different ethnic groups display multiple differences with regards to NAFLD when pertaining to its prevalence, gender distribution, and genetic predisposition. Specifically, the prevalence of NAFLD and NASH varies in individuals with different ethnicities. Hispanics exhibit the greatest prevalence of NAFLD, which is then followed by Caucasians [4,8]. Interestingly, African-Americans have the lowest prevalence of NAFLD despite having the highest prevalence of obesity and metabolic syndrome [8]. Additionally, the prevalence of NASH is also less prevalent in African-American patients with NAFLD when compared to Hispanic patients. It should be noted, though, that the prevalence of advanced fibrosis did not differ [31]. Different ethnicities also display gender differences in the distribution of NAFLD. NAFLD is more prevalent in Caucasian men when compared to Caucasian women. This pattern is not seen in the Hispanic and African-American populations [32]. Certain genetic variants, such as the I148M variant of PNPLA3, also differ between ethnicities. I148M, which is strongly associated with hepatic fat content and NAFLD, is highly frequent in Hispanics (49\%) in comparison to non-Hispanic Caucasians (23\%) and African-Americans (17\%) [18]. Studies have also demonstrated 
an increased prevalence of I148M in Indian Asians, which may explain the high prevalence of NAFLD in these populations [33]. The literature is still unclear regarding outcomes in NAFLD pertaining to the progression of cirrhosis and mortality in these different ethnic groups. For this reason, more research is warranted to further delineate the role of ethnicity and genetic predisposition in NAFLD-related outcomes. Table 2 summarizes these nonmodifiable risk factors of NAFLD.

Table 2. Nonmodifiable risk factors for NAFLD.

\begin{tabular}{lll}
\hline Factor & Association with NAFLD & Risk of Progression to NASH \\
\hline Age $[23-25,28]$ & Increases prevalence with age & Increase risk of progression to NASH \\
\hline Gender $[22-25]$ & Increase prevalence in men & Unclear \\
\hline Ethnicity $[8,18,31,33]$ & $\begin{array}{l}\text { Hispanics has the highest } \\
\text { prevalence followed by } \\
\text { Caucasians and African-American }\end{array}$ & $\begin{array}{l}\text { Association is still uncertain. } \\
\text { African-American has less prevalence of } \\
\text { NASH despite highest prevalence } \\
\text { of obesity. }\end{array}$ \\
\hline Familial predisposition $[12,14]$ & $\begin{array}{l}\text { Family history of NAFLD might } \\
\text { increases the risk }\end{array}$ & Unclear \\
\hline
\end{tabular}

\subsection{Excessive Abdominal Adipose Tissue Deposition and Obesity}

Obesity is a major modifiable risk factor for NAFLD, with over one third of the US population struggling with obesity and the remaining two thirds being overweight [34]. NAFLD is two times more prevalent in overweight individuals and four times more prevalent in the obese population. Weight gain is strongly associated with the development of NAFLD, with even a modest weight gain demonstrating an increase in the risk of developing NAFLD [35,36]. Obesity also increases the risk of NASH, fibrosis, and hepatocellular carcinoma, but current data are conflicting with some studies, failing to show an association between obesity and the progression of fibrosis [37,38]. The distribution of adipose tissue is more clearly associated to NAFLD than the amount of adipose tissue as presenting evidence displays a strong link between visceral adiposity and NAFLD. Visceral adiposity is associated with insulin resistance and increased hepatic fat content. The release of pro-inflammatory and pro-fibrogenic mediators, such as tumor necrotic factor (TNF) and leptin by visceral fat tissue, may play a role in the increased risk of fibrosis. By contrast, subcutaneous adiposity is inversely related to hepatic fat content $[39,40]$. Asian populations depict a greater occurrence of visceral adipose tissue, which predisposes them to NAFLD at a lower body mass index (BMI) [41]. A recent meta-analysis revealed that obesity (as per ethnic-specific BMI cutoff) could predict a worse long-term prognosis in patients with NAFLD [42]. Although there is a strong association between NAFLD and obesity, there is a growing number of patients with NAFLD that have a normal BMI and are referred to as having lean NAFLD. Lean NAFLD comprises 5-10\% of patients with NAFLD in the US [9]. The prevalence of lean NAFLD is higher in Europeans and Asians $[43,44]$. These patients share common risk factors with obese NAFLD, with the increased prevalence of risk factors, such as hypertension and type 2 diabetes mellitus (T2DM). Obesity also increases the risk for cardiovascular diseases. Therefore, efforts should be made to adopt healthy lifestyles and weight loss in order to prevent the morbidity and mortality associated with NAFLD.

\subsection{Insulin Resistance and Diabetes as a Risk Factor for NALFD}

Insulin resistance plays a major role in the pathogenesis of NAFLD. Adipose tissue releases pro-inflammatory cytokines, which is associated with insulin resistance. There are several other potential mechanisms of insulin resistance in NAFLD, which include increased lipogenesis, mitochondrial fatty acid oxidation, serum free fatty acids (FFA) levels, and adiponectin [45]. Patients with NAFLD have higher levels of FFA and lower levels of serum adiponectin. There is also a potential role of intestinal microbiota in insulin resistance, as composition of intestinal microbiota is distinct in patients with NAFLD patients compared to non-NAFLD patient population $[45,46]$. 
The prevalence of NAFLD is significantly higher in patients with T2DM and ranges from 30\% to $70 \%$ in various population-based studies. Overweight and obese individuals with T2DM are at an even higher risk for NAFLD. NAFLD has been reported to be as high as $76 \%$ and $56 \%$ in obese T2DM patients and biopsy-proven NASH, respectively [47]. A recent systematic review estimated the overall global prevalence of NAFLD to be around 58\% in T2DM patients [6]. Although a correlation exists between hepatic fat content and aminotransferase levels, most T2DM patients have normal serum aminotransferase levels despite having higher hepatic fat content. For this reason, T2DM can have NASH and fibrosis with normal liver chemistries [48]. T2DM patients are also at a higher risk for developing NASH and liver-related complications, including mortality related to cirrhosis $[49,50]$. Adams et al. revealed a two-fold increased risk of all-cause mortality in T2DM patients [51]. A study by Zoppini et al. revealed similar findings with a three- to five-fold higher mortality mostly related to NAFLD [52]. NAFLD is also associated with cardiovascular disease, which is highly prevalent in T2DM, and recent studies demonstrate that NAFLD patients may have a higher risk of developing microvascular complications of T2DM [53,54]. These findings suggest that screening for NAFLD should be considered in T2DM, as the presence of NASH can influence the treatment choice of T2DM. Insulin sensitizers have shown to be beneficial in improving the metabolic derangements in patients with NAFLD/NASH [55]. Multiple studies have shown the benefit of pioglitazone in improving the biochemical and histological parameters of NASH [56,57]. AASLD guidelines also recommend considering the use of pioglitazone in biopsy-proven NASH patients [58]. Liraglutide has also been studied in NASH patients, and early investigations show some benefits. This does require further research to prove its clinical efficacy in the treatment of NASH [59]. Although several studies have been done on evaluating the efficacy of metformin on liver chemistries and histology, AASLD guidelines do not recommend the use of metformin in NASH, as it has not been shown to improve liver histology [58].

\subsection{Dyslipidemia}

Lipotoxicity can occur secondary to the accumulation of fat content in non-adipose tissues and can occur secondary to insulin resistance in patients with NAFLD. It plays a pivotal role in $5 \mathrm{~h} 3$ progression of a milder form of NAFLD to NASH, as patients with NAFLD have higher levels of triglycerides, FFAs, and other types of lipids, like bile acids, free cholesterol, lysophosphatidyl cholines, and ceramides [60]. As described above, elevated levels of FFAs can also promote insulin resistance and increase the risk of NAFLD $[45,60]$. Hypertriglyceridemia (HTG) is also an independent predictor of NAFLD, and screening for NAFLD should be considered in this patient population, especially in the context of elevated liver enzymes [61,62]. Proprotein convertase subtilisin/kexin type 9 (PCSK9) is released by hepatocytes and inhibits the uptake of low-density lipoproteins (LDL). PCSK9 levels also increase with hepatic fat accumulation and are associated with a degree of steatosis [63].

Risk factors for HTG are similar to those of NAFLD and include insulin resistance and sedentary lifestyle. HTG also increases the risk of cirrhosis [64]. Studies have also shown an association between NASH and elevated levels of non-HDL cholesterol, which also increases the risk of cardiovascular diseases. Kantartzis et al., in a study of 16 patients with fatty liver and 24 control subjects, revealed that fatty liver is significantly associated with lower levels of high density [65]. Similar results were reported from the community-based Framingham Heart study, which revealed that patients with fatty liver had a higher prevalence of HTG and low HDL levels [66]. Given the association of dyslipidemia with NAFLD, several anti-hyperlipidemic drugs have been studied and have been shown to be effective in improving the histological features of NASH. Statins are the most studied drug and have been shown to prevent hepatic fibrosis. Additionally, statins also decrease the risk for cardiovascular diseases, which are highly prevalent in NAFLD patients. A meta-analysis of 259,453 patient showed that statins can decrease the progression of hepatic fibrosis, prevent hepatic decompensation in cirrhosis, and reduce all-cause mortality in patients with chronic liver disease [67]. In addition, statins have been shown to have anticancer properties and may prevent the development of hepatocellular carcinoma (HCC) [68]. 
Therefore, statins should be considered for primary or secondary prevention of cardiovascular diseases, reducing risk of cirrhosis and HCC in patients with NAFLD/NASH $[69,70]$.

\subsection{Intestinal Microbiota and Oxidative Stress}

Alteration in intestinal microbiota has been shown to play a role in the development of NAFLD. Patients with NAFLD have a higher prevalence of small intestinal bacterial overgrowth and elevated levels of tumor necrosis factor-alpha (TNF-alpha) [46,71]. A study performed on 57 patients with biopsy-proven NASH revealed that abundance of bacteroides was an independent risk factor of NASH. One possible mechanism of injury induced by intestinal microbiota is by endotoxin production, which increases the risk of steatosis [63]. Rifaximin is a minimally absorbable antibiotic, which has been shown to be effective in patients with NAFLD by improving liver enzymes and decreasing NAFLD fat score. Further research is ongoing, studying the role of intestinal microbiota in the pathogenesis of NAFLD [72]. Oxidative stress has also been shown to be a significant risk factor of NAFLD. Insulin resistance can result in hyperinsulinemia, which in turn can block the mitochondrial oxidation of fatty acids, which are then partially metabolized by the peroxisomes and microsomes, with the subsequent production of reactive oxidation species (ROS) and lipid peroxidation [73]. This production of ROS and lipid peroxidation can exhaust antioxidant enzymes and make hepatocytes susceptible to injury [74]. Several clinical studies have shown elevated oxidative stress and lipid peroxidation in patients with NAFLD [73,74]. Therefore, antioxidants can play a therapeutic role in improving the metabolic parameters in patients with NAFLD. Vitamin $\mathrm{E}$ is a potent antioxidant which has been shown to be effective in patients with NAFLD/NASH. In a randomized controlled trial of 247 patients, use of vitamin $\mathrm{E}$ was associated with improvement in nonalcoholic steatohepatitis compared to placebo [57].

\subsection{Metabolic Syndrome}

The definition of metabolic syndrome is controversial and includes risk factors for cardiovascular diseases such as hypertension, insulin resistance, obesity, and dyslipidemia [4]. There is a strong association between NAFLD and the presence of metabolic syndrome. In a meta-analysis of 411 patients, hypertension increased the risk of developing of hepatic fibrosis [38]. NAFLD has also been shown to increase the risk of arterial hypertension. A prospective cohort study of 22,090 Korean men revealed that the incidence of hypertension increases with the degree of NAFLD and also illustrated that NAFLD is an independent predictor of hypertension [50,75]. Although studies have shown some association between hypertension and NAFLD, the evidence is weaker when comparing the association of NAFLD with diabetes and obesity. Ultimately, the screening of NAFLD should still be considered in hypertensive patients due to the higher prevalence of NAFLD in this population. Table 3 summarizes major modifiable risk factor associated with NAFLD. 
Table 3. Modifiable risk factors for NAFLD.

\begin{tabular}{|c|c|c|c|}
\hline Factor & $\begin{array}{l}\text { Association with } \\
\text { NAFLD }\end{array}$ & $\begin{array}{l}\text { Risk of Progression to } \\
\text { NASH }\end{array}$ & Treatment \\
\hline Obesity [34-42] & Increase prevalence & Increase risk & Weight loss, Bariatric Surgery \\
\hline Insulin resistance $[45,46]$ & Increase prevalence & Increase risk & $\begin{array}{l}\text { Lifestyle modifications } \\
\text { Pioglitazone may improve } \\
\text { histological features of NASH. } \\
\text { Limited evidence available on } \\
\text { clinical utility of Glucagon like } \\
\text { peptide } 1 \text { antagonists (GLP-1) }\end{array}$ \\
\hline Hyperlipidemia [60-70] & Increase prevalence & Increase risk & $\begin{array}{l}\text { Statins have shown to improve } \\
\text { hepatic fibrosis. It can also } \\
\text { reduce cardiovascular mortality }\end{array}$ \\
\hline $\begin{array}{l}\text { Intestinal Microbiota and } \\
\text { oxidative stress [71-74] }\end{array}$ & $\begin{array}{l}\text { Higher prevalence of } \\
\text { small intestinal bacterial } \\
\text { overgrowth in NAFLD. }\end{array}$ & Increase risk & $\begin{array}{l}\text { Rifaximin has demonstrated } \\
\text { benefit but further research is } \\
\text { needed.Antioxidants like } \\
\text { vitamin E have shown benefit in } \\
\text { patients with NAFLD }\end{array}$ \\
\hline $\begin{array}{l}\text { Metabolic Syndrome } \\
{[38,50,75]}\end{array}$ & Increase prevalence & Increase risk & $\begin{array}{l}\text { Lifestyle modifications, statins, } \\
\text { pioglitazone, weight loss. }\end{array}$ \\
\hline
\end{tabular}

Although the components of metabolic syndrome, such as obesity, diabetes, and dyslipidemia, constitute the major risk factors associated with NAFLD, there are several other possible risk factors described in the literature. There is evidence which suggests that macro- and micro-nutrients may contribute to the epidemic of NAFLD. Specifically, increased fructose consumption has been shown to increase the risk of NAFLD [76]. Fructose is not only a major contributor in development of hepatic steatosis but is a risk factor for promoting progression to NASH [77]. It is thought to be secondary to de novo lipogenesis and inflammatory responses promoted by increasing blood glucose levels that lead to hepatocyte apoptosis via the c-Jun-N-Terminal (JNK) pathway [78]. The consumption of beverages with high sugar content has increased five-fold in the US since 1950-a concerning trend. There is evidence linking regular intake of servings with sugar-containing beverages for 6 months to features consistent with NAFLD [79]. Omega-3-fatty acids has also been shown to be effective in reducing hepatic fat accumulation in patients with NAFLD. A meta-analysis including 10 randomized controlled trials with 577 patients of NAFLD revealed Omega-3-fatty acids to be effective in reducing hepatic fat content in patients with NAFLD and NASH [80]. The Mediterranean diet has also been shown to be beneficial in patients with NAFLD. The Mediterranean diet consists of fruits, vegetables, olive oil, and nuts, which are high in omega-3-fatty acids and antioxidants. Baratta et al., in a study including 584 patients, revealed adherence to the Mediterranean diet was associated with lower insulin resistance and reduced risk of NAFLD [81]. Therefore, experts recommend the use of the Mediterranean diet for weight loss and protection against NAFLD $[82,83]$. There are several other micro- and macronutrients that may influence the development of NAFLD, but detailed discussion of the nutrients is beyond the scope of this review. Other comorbidities, such as hypothyroidism, hypopituitarism, polycystic ovarian disease, and obstructive sleep apnea, that are also associated with NAFLD require further investigations to strengthen their associations [58].

\section{Diagnostic Challenges in NAFLD}

The diagnosis of NAFLD involves an appropriate clinical history, radiographic and laboratory investigations, and histologic information. Diagnosing NAFLD requires evidence of hepatic steatosis in the absence of significant alcohol consumption, other causes of hepatic steatosis, and coexisting liver diseases. The use of abdominal imaging can be used to diagnose NAFLD, thus limiting the need for invasive procedures, such as liver biopsies. However, a liver biopsy is useful when differentiating between simple steatosis (NAFL) and NASH. For this reason, a liver biopsy can assist with determining the risk of disease progression and subsequent management of NAFLD $[58,84]$. 


\subsection{Role of Liver Biopsy in the Diagnosis of NAFLD}

The early diagnosis of NASH has crucial management implications, as patients can benefit from newly approved medications and off-label therapies to retard the progression of liver disease $[57,67]$. Unfortunately, a liver biopsy is needed to confirm the characteristic histologic features of NASH prior to making a diagnosis. For this reason, the considerable disease burden of NASH in the US and the invasive nature of a liver biopsy has prompted experts to recommend its selective use only in NAFLD patients with higher likelihoods of progression to NASH. Therefore, an individualized assessment considering the risks and benefits regarding a diagnostic liver biopsy is warranted. Generally, a liver biopsy is reserved for scenarios where the clinical suspicion of NAFLD is high but noninvasive modalities are inconclusive, where there is evidence of cirrhosis or in patients who are at a high risk for advanced fibrosis. The NAFLD activity score (NAS) is widely used for the histopathological diagnosis of NASH [58]. The NAS score considers three important histological features in a biopsy specimen which include steatosis, hepatocellular ballooning, and lobular inflammation. Table 4 describes the NAS score for the diagnosis of NASH. The CRN scoring system is widely used to assess the extent of fibrosis in biopsy specimens in patients with NAFLD [84]. Table 5 describes the CRN histological scoring system for the diagnosis of NAFLD. An important consideration is inter-observer variability that can occur during the histologic evaluation of liver biopsy samples even among experienced pathologists $[84,85]$. The lack of agreement between pathologists regarding hepatocellular ballooning or sampling error is a limitation and may explain the lower number of patients meeting the entry criteria for clinical trials.

Table 4. The NAFLD activity score (NAS) for the histopathologic diagnosis of nonalcoholic steatohepatitis (NASH) [84].

\begin{tabular}{ccc}
\hline Histological Features & Extent & Score \\
\hline & Extent of involvement of parenchyma by steatosis & 0 \\
Steatosis & $<5 \%$ & 1 \\
& $5 \%-33 \%$ & 2 \\
& $33 \%-66 \%$ & 3 \\
\hline \multirow{2}{*}{ Ballooning } & $>66 \%$ & 0 \\
& No ballooned cells & 1 \\
& Few ballooned cells & 2 \\
\hline \multirow{2}{*}{ Lobular Inflammation } & Many cells with ballooning & 0 \\
& No inflammatory Foci per 200 Field & 1 \\
& $<2$ foci per 200 field & 2 \\
NAS & $>4$ foci per 200 field & 3 \\
\hline & Sum of steatosis + ballooning + lobular inflammation & NASH unlikely \\
& Score 0-2 & Borderline \\
& Score 3-4 & Likely NASH \\
\hline
\end{tabular}

Table 5. CRN histological scoring system for grading of fibrosis in NAFLD [84].

\begin{tabular}{cc}
\hline Stage of Fibrosis & CRN Scoring System \\
\hline 0 & No fibrosis \\
Stage 1 A & Mild perisinusoidal \\
Stage 1 B & Moderate perisinusoidal \\
Stage 1 C & Portal/periportal fibrosis \\
Stage 2 & Perisinusoidal and portal/periportal fibrosis \\
Stage 3 & Bridging fibrosis \\
Stage 4 & Cirrhosis \\
\hline
\end{tabular}




\subsection{Noninvasive Markers for the Detection of Fibrosis}

The limitations of liver biopsy, the high prevalence of NAFLD, and the lack of agreement on the clinical predictors of NASH have created a niche for next-generation noninvasive biomarkers and imaging modalities to help to differentiate NAFLD from NASH. These biomarkers can be categorized into indirect and direct markers of fibrosis, as illustrated in Table 6. Some examples of indirect markers include aminotransferases, cytokeratin-18, and multiple scoring systems which combine certain laboratory markers, such as the aspartate aminotransferase (AST)/platelet ratio index (APRI), NAFLD Fibrosis Score (NFS), FIB-4 index, and Fibrotest. Direct markers of fibrosis comprise the extracellular matrix (ECM). such as hyaluronic acid (HA), fibronectin, elastin, and laminin, which form in the setting of persistent hepatocyte injury and have also been incorporated into certain scores. These markers are discussed in detail below.

Table 6. Noninvasive serologic tests for the diagnosis of NAFLD.

\begin{tabular}{ccc}
\hline Serologic Test & Component of the Test & Clinical Utility \\
\hline Aminotransferases [86] & ALT and AST & May be elevated in NAFLD patients \\
\hline Cytokeratin-18 [87] & Cytokeratin-18 & Elevated levels in NASH patients \\
\hline AST/platelet ratio index (APRI) [88] & AST and platelets & Predicting fibrosis \\
\hline NAFLD fibrosis score (NFS) [89,90] & $\begin{array}{c}\text { Age, BMI, blood glucose levels, } \\
\text { aminotransferase levels, platelet count, } \\
\text { and albumin }\end{array}$ & $\begin{array}{c}\text { Predicting advanced fibrosis and } \\
\text { clinical outcomes in NAFLD patients }\end{array}$ \\
\hline FIB-4 index [90,91] & Age, AST, ALT and platelet count & $\begin{array}{c}\text { Predicting advanced fibrosis and } \\
\text { clinical outcomes in NAFLD patients }\end{array}$ \\
\hline FibroTest [92-94] & $\begin{array}{c}\text { Age, sex, alpha-2-macroglobulin, } \\
\text { haptoglobin, gamma globulin, } \\
\text { apolipoprotein A1, gamma glutamyl } \\
\text { transferase and total bilirubin levels }\end{array}$ & Predicting extent of fibrosis \\
\hline ActiTest [93,94] & $\begin{array}{c}\text { Age, sex, alpha-2-macroglobulin, } \\
\text { haptoglobin, gamma globulin, } \\
\text { apolipoprotein A1, gamma glutamyl } \\
\text { transferase and total bilirubin and } \\
\text { ALT levels }\end{array}$ & Predicting necroinflammatory activity \\
\hline FibroSpect II [97] & $\begin{array}{c}\text { Matrix metalloproteinase 1 (MMP-1), HA } \\
\text { and amino-terminal propeptide of type III } \\
\text { collagen level }\end{array}$ & Predicting extent of fibrosis \\
\hline (ELF) [95,96] panel & $\begin{array}{c}\text { Hyaluronic acid, tissue inhibitor of } \\
\text { metalloproteinase-1 (TIMP-1), and } \\
\text { alpha-2-macroglobulin. }\end{array}$ & Predicting extent of fibrosis \\
\hline
\end{tabular}

\subsection{Indirect Markers of Fibrosis}

\subsubsection{Aminotransferases}

Elevations of alanine aminotransferase levels (ALT) and aspartate aminotransferases (AST) can be found in patients with NAFLD, although normal levels do not exclude the presence of NAFLD or NASH. When elevated, these patients usually have AST to ALT ratios of less than 1, unlike alcoholic liver disease, which typically demonstrates ratios greater than 2. A retrospective study by Verma et al. reported the prevalence of NASH in patients with elevated ALT levels ( $>35 \mathrm{U} / \mathrm{L}$ ) to be $28.9 \%$ compared to the normal ALT group, which had a frequency close to $10.7 \%$. Additionally, there was no difference in the rate of advanced fibrosis between the normal and elevated ALT group. The study also revealed that ALT levels two times the upper limit of normal have limited utility in predicting NASH, with a sensitivity and specificity of $50 \%$ and $61 \%$, respectively [86].

\subsubsection{Cytokeratin- 18}

Multiple studies have found elevated levels of cytokeratin-18 (CK-18) fragments in patients with NASH and have shown that elevated levels of CK-18 can be a predictor of NASH in patients with 
NAFLD [87]. Although promising, the commercial unavailability of these tests and the lack of a clear cutoff point are factors which limit its clinical use in the diagnosis of NASH. Further studies are required to further establish the clinical utility of CK-18 in NAFLD.

\subsubsection{AST/Platelet Ratio Index (APRI)}

APRI is a ratio of ALT levels and platelets that has been used to predict advance fibrosis primarily in HIV and HCV patients with limited evidence in the NAFLD population. A meta-analysis including 40 studies showed that the APRI ratio had a sensitivity and specificity of $77 \%$ and $72 \%$, respectively, when predicting for significant fibrosis [88].

\subsubsection{NAFLD Fibrosis Score}

The NAFLD fibrosis score (NFS) is a score used to evaluate the possibility of advanced fibrosis in patients with NAFLD and is also used to predict outcomes in patients with NAFLD. NFS considers a patient's age, BMI, blood glucose levels, aminotransferase levels, platelet count, and albumin. In a validation study, a high NAFLD fibrosis score cutoff $(>0.676)$ was associated with a positive predictive value of 90 percent, and a low cutoff value $(<-1.455)$ was associated with a negative predictive value of 93 percent [89]. A retrospective study by Angulo et al. in patients with NAFLD revealed the area under the ROC curve using NFS was 0.86 for predicting adverse liver-related outcomes and 0.70 for predicting mortality or liver transplantation [90].

\subsubsection{FIB-4 Index}

FIB-4 incorporates a patient's age, AST, ALT, and platelet count to evaluate advanced fibrosis. FIB-4 has been shown to be better at predicting advanced fibrosis when compared to other serologic tests [91]. FIB-4 is also helpful in predicting outcomes in patients with NAFLD. The previous retrospective study by Angulo et al. further evaluated the FIB-4 index and revealed the area under the ROC curve was 0.81 for predicting adverse liver-related outcomes and 0.67 for predicting death or liver transplantation [90].

\subsubsection{FibroTest, FibroSure, and ActiTest}

FibroTest includes the assessment of a patient's age, sex, alpha-2-macroglobulin, haptoglobin, gamma globulin, apolipoprotein A1, gamma glutamyl transferase, and total bilirubin levels to predict the extent of fibrosis [92,93]. ActiTest is similar to FibroTest, but it incorporates ALT levels [93]. A meta-analysis including 1570 patients revealed that these noninvasive proprietary tests were reliable alternatives to liver biopsy in patients with chronic HCV [94].

\subsection{Direct Markers for Fibrosis}

The liver is capable of hepatic regeneration when injured. When exposed to severe insults, however, hepatocytes can be replaced by components of the extracellular matrix (ECM), such as hyaluronic acid (HA), fibronectin, elastin, and laminin. These markers of ECM are attractive targets to predict fibrosis in NAFLD patients and are currently under investigation [95-97].

\subsubsection{Enhanced Liver Fibrosis panel (ELF)}

ELF is a commercially available panel that incorporates matrix turnover markers, such as matrix metalloproteinase 1 (MMP-1), HA, and amino-terminal propeptide of type III collagen level to predict liver fibrosis [95]. ELF is marginally better than NFS in predicting fibrosis, but the combination of these two tests has been shown to remarkably enhance the detection of fibrosis [96]. 


\subsubsection{FibroSpect II}

The FibroSpect II panel consists of serum HA, tissue inhibitor of metalloproteinase-1 (TIMP-1), and alpha-2-macroglobulin. In a retrospective of study of 129 morbidly obese patients undergoing gastric bypass, Fibrospect II had a negative predictive value of $100 \%$ to predict advance fibrosis and can be used as a useful panel to rule out significant fibrosis in NAFLD patients [97].

\subsection{Abdominal Imaging Modalities for Assessing Hepatic Steatosis}

A variety of imaging modalities can be utilized for the diagnosis of NAFLD as displayed in Table 7. These range from common radiologic techniques, such as ultrasound (US), computed tomography (CT), and magnetic resonance imaging (MRI), to methods measuring hepatic stiffness, such as magnetic resonance elastography (MRE) and Transient elastography (TE) (Fibroscan).

Table 7. Imaging modalities for the diagnosis of NAFLD.

\begin{tabular}{|c|c|c|}
\hline Imaging Modality & Clinical Utility & Limitations \\
\hline CT abdomen [99] & $\begin{array}{l}\text { Limited clinical utility in } \\
\text { diagnosing NAFLD }\end{array}$ & $\begin{array}{l}\text { Radiation hazard, introduces } \\
\text { contrast-related risks, has low } \\
\text { sensitivity for hepatic fat mapping }\end{array}$ \\
\hline $\begin{array}{l}\text { Magnetic resonance spectroscopy } \\
{[99-101]}\end{array}$ & Allows for quantification of hepatic fat & Not available on all scanner \\
\hline $\begin{array}{l}\text { Transient Elastography (Fibroscan) } \\
{\left[\begin{array}{l}{[102,103]}\end{array}\right.}\end{array}$ & $\begin{array}{c}\text { Sensitivity of } 88 \% \text { with a negative } \\
\text { predictive value of } 90 \% \text { in detecting } \\
\text { advanced fibrosis }\end{array}$ & $\begin{array}{l}\text { Presence of ascites, obese patients or } \\
\text { presence of acute inflammation }\end{array}$ \\
\hline $\begin{array}{c}\text { Shear wave elastography (SWE) } \\
\text { [106] }\end{array}$ & $\begin{array}{l}\text { Sensitivity of } 90 \% \text { and the specificity } \\
\text { of } 88 \% \text { in detecting advanced fibrosis }\end{array}$ & $\begin{array}{l}\text { Limited evidence available current } \\
\text { and needs further research on its } \\
\text { clinical utility }\end{array}$ \\
\hline
\end{tabular}

\subsubsection{Ultrasound and Computed Tomography of the Abdomen}

US of the abdomen is the most widely available test, with a meta-analysis reporting its sensitivity and specificity for diagnosing fatty liver disease as high as $85 \%$ and $94 \%$ when compared to liver biopsy [98]. Additionally, US is a noninvasive modality that does not pose contrast-related risks and is preferred by patients over more invasive methods. US is, however, operator-dependent and thus lacks sensitivity in NAFLD patients with less than 30\% steatosis on liver biopsy. Sensitivity of US in detecting hepatic steatosis also decreases in morbidly obese patients. Computed tomography (CT) is another imaging modality but requires radiation and contrast exposure, has lower sensitivity for hepatic fat mapping, and is expensive [8].

\subsubsection{Magnetic Resonance Imaging and Magnetic Resonance Spectroscopy}

Magnetic resonance imaging (MRI) and magnetic resonance spectroscopy (MRS) provide the highest precision (sensitivity and specificity) in quantifying steatosis and liver fat mapping when compared to other imaging modalities. With promising initial data, MRI and MRS may become the gold standard for the diagnosis and management of NAFLD in the near future, although the cost of such imaging is still a significant health and economic barrier [99-101].

Alternatively, hepatic stiffness measurements with noninvasive methods like MRE and TE can also be used to stratify patients into advanced and nonadvanced fibrosis groups [102,104,105,107]. 


\subsubsection{Transient Elastography (Fibroscan) and Magnetic Resonance Elastography (MRE)}

Fibroscan and MRE are the most accurate noninvasive tests to evaluate hepatic stiffness and to differentiate advanced and nonadvanced hepatic fibrosis. Fibroscan has a sensitivity of $88 \%$, with a negative predictive value of $90 \%$ in detecting advanced fibrosis [102]. Comparatively, MRE has a sensitivity of $86 \%$ and specificity of $91 \%$ for diagnosing advanced fibrosis by using a stiffness cutoff of 3.63 Kilopascals [104]. MRE can also help to identify individuals with steatohepatitis, even before the onset of significant fibrosis. NAFLD with inflammation but without fibrosis demonstrates greater hepatic stiffness than simple steatosis and a lower mean stiffness than NAFLD with fibrosis [107]. MRE is also superior to Fibroscan in diagnosing cirrhosis [105]. Limitations for using MRE include limited availability and expertise to interpret the results, cost of the procedure, inability to be used in the presence of metal implants, and patient-limiting factors, such as size and claustrophobia [103]. Although Fibroscan is more convenient to use, its clinical utility is limited in patients with ascites, excessive abdominal fat disposition or in the presence of acute inflammation [106]. For these reasons, Fibroscan is a more appropriate modality in non-obese patients, while MRE should be considered in patients with morbid obesity for the detection of advanced fibrosis.

In summary, the diagnosis of NAFLD can be made by combining appropriate noninvasive serologic tests and imaging modalities and may help in reducing the need for liver biopsies. Studies have shown that these noninvasive markers of liver fibrosis can differentiate between the absence of fibrosis and mild fibrosis from advanced bridging fibrosis or cirrhosis. However, noninvasive tests lack the ability to reliably detect intermediate or moderate grade fibrosis and are not useful in staging the extent of hepatic injury. For this reason, liver biopsy remains the gold standard test when diagnosing NAFLD and when evaluating advanced fibrosis and should be considered when the diagnosis remains unclear despite noninvasive testing.

\section{Conclusions}

NAFLD is a complex entity that overlaps significantly with insulin resistance and inflammatory states, including the components of metabolic syndrome. Furthermore, there is emerging evidence highlighting the importance of genetic predisposition, environmental exposures, clinical factors, and demographical differences in NAFLD. Several studies illustrate the importance of nonpharmacologic and pharmacologic measures in reducing the incidence and progression of NAFLD. The need for early intervention can only be stressed further with evidence linking NALD with increased cardiovascular mortality. For these reasons, efforts should be made to effectively screen and treat for NAFLD and its associated risk factors to impede the progression of this serious disease, which currently lacks a definite treatment.

Author Contributions: U.I., B.J.P. and D.A. performed the literature search and prepared the body of the manuscript. D.K. and A.A. is a senior author who provided critical comments and updated the body of the manuscript with recent literature and reference. All the authors approved the final version of the manuscript.

Funding: This research received no external funding.

Conflicts of Interest: The authors declare no conflict of interest.

\section{References}

1. Younossi, Z.M.; Stepanova, M.; Afendy, M.; Fang, Y.; Younossi, Y.; Mir, H.; Srishord, M. Changes in the prevalence of the most common causes of chronic liver diseases in the United States from 1988 to 2008. Clin. Gastroenterol. Hepatol. 2011, 9, 524-530. [CrossRef] [PubMed]

2. Younossi, Z.; Anstee, Q.M.; Marietti, M.; Hardy, T.; Henry, L.; Eslam, M.; George, J.; Bugianesi, E. Global burden of NAFLD and NASH: Trends, predictions, risk factors and prevention. Nat. Rev. Gastroenterol. Hepatol. 2018, 15, 11-20. [CrossRef] [PubMed] 
3. Younossi, Z.M.; Blissett, D.; Blissett, R.; Henry, L.; Stepanova, M.; Younossi, Y.; Racila, A.; Hunt, S.; Beckerman, R. The economic and clinical burden of nonalcoholic fatty liver disease in the United States and Europe. Hepatology 2016, 64, 1577-1586. [CrossRef]

4. Younossi, Z.M.; Koenig, A.B.; Abdelatif, D.; Fazel, Y.; Henry, L.; Wymer, M. Global epidemiology of nonalcoholic fatty liver disease-Meta-analytic assessment of prevalence, incidence, and outcomes. Hepatology 2016, 64, 73-84. [CrossRef] [PubMed]

5. Ruhl, C.E.; Everhart, J.E. Fatty liver indices in the multiethnic United States National Health and Nutrition Examination Survey. Aliment. Pharmacol. Ther. 2015, 41, 65-76. [CrossRef]

6. Golabi, P.; Fukui, N.; de Avila, L.; Paik, J.; Srishord, M.; Younossi, Z.M. The Global Epidemiology of Non-alcoholic Fatty Liver Disease in Patients with Type 2 Diabetes Mellitus: A Systematic Review and Meta-analysis. Hepatology 2017, 66, 1177-1178.

7. Yki-Järvinen, $\mathrm{H}$. Non-alcoholic fatty liver disease as a cause and a consequence of metabolic syndrome. Lancet Diabetes Endocrinol. 2014, 2, 901-910. [CrossRef]

8. Non-alcoholic Fatty Liver Disease Study Group; Lonardo, A.; Bellentani, S.; Argo, C.K.; Ballestri, S.; Byrne, C.D.; Caldwell, S.H.; Cortez-Pinto, H.; Grieco, A.; Machado, M.V.; et al. Epidemiological modifiers of non-alcoholic fatty liver disease: Focus on high-risk groups. Dig. Liver Dis. 2015, 47, 997-1006. [CrossRef]

9. Younossi, Z.M.; Stepanova, M.; Negro, F.; Hallaji, S.; Younossi, Y.; Lam, B.; Srishord, M. Nonalcoholic fatty liver disease in lean individuals in the United States. Medicine 2012, 91, 319-327. [CrossRef]

10. Yang, J.D.; Abdelmalek, M.F.; Pang, H.; Guy, C.D.; Smith, A.D.; Diehl, A.M.; Suzuki, A. Gender and Menopause Impact Severity of Fibrosis Among Patients with Nonalcoholic Steatohepatitis. Hepatology 2014, 59, 1406-1414. [CrossRef]

11. Estes, C.; Razavi, H.; Loomba, R.; Younossi, Z.; Sanyal, A.J. Modeling the epidemic of nonalcoholic fatty liver disease demonstrates an exponential increase in burden of disease. Hepatology 2018, 67, 123-133. [CrossRef] [PubMed]

12. Struben, V.M.; Hespenheide, E.E.; Caldwell, S.H. Nonalcoholic steatohepatitis and cryptogenic cirrhosis within kindreds. Am. J. Med. 2000, 108, 9-13. [CrossRef]

13. Brouwers, M.C.G.J.; Cantor, R.M.; Kono, N.; Yoon, J.L.; van der Kallen, C.J.H.; Bilderbeek-Beckers, M.A.L.; van Greevenbroek, M.M.J.; Lusis, A.J.; de Bruin, T.W.A. Heritability and genetic loci of fatty liver in familial combined hyperlipidemia. J. Lipid Res. 2006, 47, 2799-2807. [CrossRef] [PubMed]

14. Loomba, R.; Rao, F.; Zhang, L.; Khandrika, S.; Ziegler, M.G.; Brenner, D.A.; O'Connor, D.T. Genetic covariance between gamma-glutamyl transpeptidase and fatty liver risk factors: Role of beta2-adrenergic receptor genetic variation in twins. Gastroenterology 2010, 139, 836-845. [CrossRef] [PubMed]

15. Sookoian, S.; Pirola, C.J. Meta-analysis of the influence of I148M variant of patatin-like phospholipase domain containing 3 gene (PNPLA3) on the susceptibility and histological severity of nonalcoholic fatty liver disease. Hepatology 2011, 53, 1883-1894. [CrossRef] [PubMed]

16. Rotman, Y.; Koh, C.; Zmuda, J.M.; Kleiner, D.E.; Liang, T.J.; NASH; CRN. The association of genetic variability in patatin-like phospholipase domain-containing protein 3 (PNPLA3) with histological severity of nonalcoholic fatty liver disease. Hepatology 2010, 52, 894-903. [CrossRef] [PubMed]

17. Speliotes, E.K.; Butler, J.L.; Palmer, C.D.; Voight, B.F.; GIANT Consortium; MIGen Consortium; NASH CRN; Hirschhorn, J.N. PNPLA3 variants specifically confer increased risk for histologic nonalcoholic fatty liver disease but not metabolic disease. Hepatology 2010, 52, 904-912. [CrossRef] [PubMed]

18. Romeo, S.; Kozlitina, J.; Xing, C.; Pertsemlidis, A.; Cox, D.; Pennacchio, L.A.; Boerwinkle, E.; Cohen, J.C.; Hobbs, H.H. Genetic variation in PNPLA3 confers susceptibility to nonalcoholic fatty liver disease. Nat. Genet. 2008, 40, 1461-1465. [CrossRef]

19. Speliotes, E.K.; Yerges-Armstrong, L.M.; Wu, J.; Hernaez, R.; Kim, L.J.; Palmer, C.D.; Gudnason, V.; Eiriksdottir, G.; Garcia, M.E.; Launer, L.J.; et al. GOLD Consortium Genome-wide association analysis identifies variants associated with nonalcoholic fatty liver disease that have distinct effects on metabolic traits. PLoS Genet. 2011, 7, e1001324. [CrossRef]

20. Kozlitina, J.; Smagris, E.; Stender, S.; Nordestgaard, B.G.; Zhou, H.H.; Tybjærg-Hansen, A.; Vogt, T.F.; Hobbs, H.H.; Cohen, J.C. Exome-wide association study identifies a TM6SF2 variant that confers susceptibility to nonalcoholic fatty liver disease. Nat. Genet. 2014, 46, 352-356. [CrossRef] 
21. Liu, Y.-L.; Reeves, H.L.; Burt, A.D.; Tiniakos, D.; McPherson, S.; Leathart, J.B.S.; Allison, M.E.D.; Alexander, G.J.; Piguet, A.-C.; Anty, R.; et al. TM6SF2 rs58542926 influences hepatic fibrosis progression in patients with non-alcoholic fatty liver disease. Nat. Commun. 2014, 5, 4309. [CrossRef] [PubMed]

22. Williams, C.D.; Stengel, J.; Asike, M.I.; Torres, D.M.; Shaw, J.; Contreras, M.; Landt, C.L.; Harrison, S.A. Prevalence of nonalcoholic fatty liver disease and nonalcoholic steatohepatitis among a largely middle-aged population utilizing ultrasound and liver biopsy: A prospective study. Gastroenterology 2011, 140, 124-131. [CrossRef] [PubMed]

23. Fan, J.-G.; Zhu, J.; Li, X.-J.; Chen, L.; Li, L.; Dai, F.; Li, F.; Chen, S.-Y. Prevalence of and risk factors for fatty liver in a general population of Shanghai, China. J. Hepatol. 2005, 43, 508-514. [CrossRef] [PubMed]

24. Hu, X.; Huang, Y.; Bao, Z.; Wang, Y.; Shi, D.; Liu, F.; Gao, Z.; Yu, X. Prevalence and factors associated with nonalcoholic fatty liver disease in Shanghai work-units. BMC Gastroenterol. 2012, 12, 123. [CrossRef]

25. Eguchi, Y.; Hyogo, H.; Ono, M.; Mizuta, T.; Ono, N.; Fujimoto, K.; Chayama, K.; Saibara, T. JSG-NAFLD Prevalence and associated metabolic factors of nonalcoholic fatty liver disease in the general population from 2009 to 2010 in Japan: A multicenter large retrospective study. J. Gastroenterol. 2012, 47, 586-595. [CrossRef] [PubMed]

26. Angulo, P.; Keach, J.C.; Batts, K.P.; Lindor, K.D. Independent predictors of liver fibrosis in patients with nonalcoholic steatohepatitis. Hepatology 1999, 30, 1356-1362. [CrossRef] [PubMed]

27. Matteoni, C.A.; Younossi, Z.M.; Gramlich, T.; Boparai, N.; Liu, Y.C.; McCullough, A.J. Nonalcoholic fatty liver disease: A spectrum of clinical and pathological severity. Gastroenterology 1999, 116, 1413-1419.

28. Argo, C.K.; Northup, P.G.; Al-Osaimi, A.M.S.; Caldwell, S.H. Systematic review of risk factors for fibrosis progression in non-alcoholic steatohepatitis. J. Hepatol. 2009, 51, 371-379. [CrossRef] [PubMed]

29. Bedogni, G.; Miglioli, L.; Masutti, F.; Castiglione, A.; Crocè, L.S.; Tiribelli, C.; Bellentani, S. Incidence and natural course of fatty liver in the general population: The Dionysos study. Hepatology 2007, 46, 1387-1391. [CrossRef]

30. Ong, J.P.; Pitts, A.; Younossi, Z.M. Increased overall mortality and liver-related mortality in non-alcoholic fatty liver disease. J. Hepatol. 2008, 49, 608-612. [CrossRef]

31. Kallwitz, E.R.; Guzman, G.; TenCate, V.; Vitello, J.; Layden-Almer, J.; Berkes, J.; Patel, R.; Layden, T.J.; Cotler, S.J. The histologic spectrum of liver disease in African-American, non-Hispanic white, and Hispanic obesity surgery patients. Am. J. Gastroenterol. 2009, 104, 64-69. [CrossRef]

32. Browning, J.D.; Szczepaniak, L.S.; Dobbins, R.; Nuremberg, P.; Horton, J.D.; Cohen, J.C.; Grundy, S.M.; Hobbs, H.H. Prevalence of hepatic steatosis in an urban population in the United States: Impact of ethnicity. Hepatology 2004, 40, 1387-1395. [CrossRef] [PubMed]

33. Bhatt, S.P.; Nigam, P.; Misra, A.; Guleria, R.; Pandey, R.M.; Pasha, M.A.Q. Genetic variation in the patatin-like phospholipase domain-containing protein-3 (PNPLA-3) gene in Asian Indians with nonalcoholic fatty liver disease. Metab. Syndr. Relat. Disord. 2013, 11, 329-335. [CrossRef] [PubMed]

34. Nguyen, D.M.; El-Serag, H.B. The epidemiology of obesity. Gastroenterol. Clin. North Am. 2010, 39, 1-7. [CrossRef]

35. Júnior, W.S.; Nonino-Borges, C.B. Clinical predictors of different grades of nonalcoholic fatty liver disease. Obes. Surg. 2012, 22, 248-252. [CrossRef] [PubMed]

36. Zelber-Sagi, S.; Lotan, R.; Shlomai, A.; Webb, M.; Harrari, G.; Buch, A.; Nitzan Kaluski, D.; Halpern, Z.; Oren, R. Predictors for incidence and remission of NAFLD in the general population during a seven-year prospective follow-up. J. Hepatol. 2012, 56, 1145-1151. [CrossRef] [PubMed]

37. Calle, E.E.; Rodriguez, C.; Walker-Thurmond, K.; Thun, M.J. Overweight, obesity, and mortality from cancer in a prospectively studied cohort of U.S. adults. N. Engl. J. Med. 2003, 348, 1625-1638. [CrossRef] [PubMed]

38. Singh, S.; Allen, A.M.; Wang, Z.; Prokop, L.J.; Murad, M.H.; Loomba, R. Fibrosis progression in nonalcoholic fatty liver vs nonalcoholic steatohepatitis: A systematic review and meta-analysis of paired-biopsy studies. Clin. Gastroenterol. Hepatol. 2015, 13, 643-654. [CrossRef]

39. Kabir, M.; Catalano, K.J.; Ananthnarayan, S.; Kim, S.P.; Van Citters, G.W.; Dea, M.K.; Bergman, R.N. Molecular evidence supporting the portal theory: A causative link between visceral adiposity and hepatic insulin resistance. Am. J. Physiol. Endocrinol. Metab. 2005, 288, E454-E461. [CrossRef]

40. Rocha, P.M.; Barata, J.T.; Minderico, C.S.; Silva, A.M.; Teixeira, P.J.; Sardinha, L.B. Visceral abdominal and subfascial femoral adipose tissue have opposite associations with liver fat in overweight and obese premenopausal caucasian women. J. Lipids 2011, 2011, 154672. [CrossRef] 
41. Wong, R.J.; Ahmed, A. Obesity and non-alcoholic fatty liver disease: Disparate associations among Asian populations. World J. Hepatol. 2014, 6, 263-273. [CrossRef] [PubMed]

42. Lu, F.-B.; Hu, E.-D.; Xu, L.-M.; Chen, L.; Wu, J.-L.; Li, H.; Chen, D.-Z.; Chen, Y.-P. The relationship between obesity and the severity of non-alcoholic fatty liver disease: Systematic review and meta-analysis. Expert Rev. Gastroenterol. Hepatol. 2018, 12, 491-502. [CrossRef]

43. Hagström, H.; Nasr, P.; Ekstedt, M.; Hammar, U.; Stål, P.; Hultcrantz, R.; Kechagias, S. Risk for development of severe liver disease in lean patients with nonalcoholic fatty liver disease: A long-term follow-up study. Hepatol. Commun. 2018, 2, 48-57. [CrossRef] [PubMed]

44. Leung, J.C.-F.; Loong, T.C.-W.; Wei, J.L.; Wong, G.L.-H.; Chan, A.W.-H.; Choi, P.C.-L.; Shu, S.S.-T.; Chim, A.M.-L.; Chan, H.L.-Y.; Wong, V.W.-S. Histological severity and clinical outcomes of nonalcoholic fatty liver disease in nonobese patients. Hepatology 2017, 65, 54-64. [CrossRef] [PubMed]

45. Khan, R.; Bril, F.; Cusi, K.; Newsome, P.N. Modulation of Insulin Resistance in NAFLD. Hepatology 2018. [CrossRef]

46. Boursier, J.; Mueller, O.; Barret, M.; Machado, M.; Fizanne, L.; Araujo-Perez, F.; Guy, C.D.; Seed, P.C.; Rawls, J.F.; David, L.A.; et al. The severity of nonalcoholic fatty liver disease is associated with gut dysbiosis and shift in the metabolic function of the gut microbiota. Hepatology 2016, 63, 764-775. [CrossRef]

47. Portillo-Sanchez, P.; Bril, F.; Maximos, M.; Lomonaco, R.; Biernacki, D.; Orsak, B.; Subbarayan, S.; Webb, A.; Hecht, J.; Cusi, K. High Prevalence of Nonalcoholic Fatty Liver Disease in Patients with Type 2 Diabetes Mellitus and Normal Plasma Aminotransferase Levels. J. Clin. Endocrinol. Metab. 2015, 100, 2231-2238. [CrossRef]

48. Maximos, M.; Bril, F.; Portillo Sanchez, P.; Lomonaco, R.; Orsak, B.; Biernacki, D.; Suman, A.; Weber, M.; Cusi, K. The role of liver fat and insulin resistance as determinants of plasma aminotransferase elevation in nonalcoholic fatty liver disease. Hepatology 2015, 61, 153-160. [CrossRef]

49. Anstee, Q.M.; Targher, G.; Day, C.P. Progression of NAFLD to diabetes mellitus, cardiovascular disease or cirrhosis. Nat. Rev. Gastroenterol. Hepatol. 2013, 10, 330-344. [CrossRef]

50. Sung, K.-C.; Wild, S.H.; Byrne, C.D. Development of new fatty liver, or resolution of existing fatty liver, over five years of follow-up, and risk of incident hypertension. J. Hepatol. 2014, 60, 1040-1045. [CrossRef]

51. Adams, L.A.; Harmsen, S.; St Sauver, J.L.; Charatcharoenwitthaya, P.; Enders, F.B.; Therneau, T.; Angulo, P. Nonalcoholic fatty liver disease increases risk of death among patients with diabetes: A community-based cohort study. Am. J. Gastroenterol. 2010, 105, 1567-1573. [CrossRef]

52. Zoppini, G.; Fedeli, U.; Gennaro, N.; Saugo, M.; Targher, G.; Bonora, E. Mortality from chronic liver diseases in diabetes. Am. J. Gastroenterol. 2014, 109, 1020-1025. [CrossRef]

53. Targher, G.; Bertolini, L.; Rodella, S.; Tessari, R.; Zenari, L.; Lippi, G.; Arcaro, G. Nonalcoholic fatty liver disease is independently associated with an increased incidence of cardiovascular events in type 2 diabetic patients. Diabetes Care 2007, 30, 2119-2121. [CrossRef] [PubMed]

54. Targher, G.; Chonchol, M.B.; Byrne, C.D. CKD and nonalcoholic fatty liver disease. Am. J. Kidney Dis. 2014, 64, 638-652. [CrossRef] [PubMed]

55. Raschi, E.; Mazzotti, A.; Poluzzi, E.; De Ponti, F.; Marchesini, G. Pharmacotherapy of type 2 diabetes in patients with chronic liver disease: Focus on nonalcoholic fatty liver disease. Expert Opin. Pharmacother. 2018, 19, 1903-1914. [CrossRef] [PubMed]

56. Aithal, G.P.; Thomas, J.A.; Kaye, P.V.; Lawson, A.; Ryder, S.D.; Spendlove, I.; Austin, A.S.; Freeman, J.G.; Morgan, L.; Webber, J. Randomized, placebo-controlled trial of pioglitazone in nondiabetic subjects with nonalcoholic steatohepatitis. Gastroenterology 2008, 135, 1176-1184. [CrossRef] [PubMed]

57. Sanyal, A.J.; Chalasani, N.; Kowdley, K.V.; McCullough, A.; Diehl, A.M.; Bass, N.M.; Neuschwander-Tetri, B.A.; Lavine, J.E.; Tonascia, J.; Unalp, A.; et al. NASH CRN Pioglitazone, vitamin E, or placebo for nonalcoholic steatohepatitis. N. Engl. J. Med. 2010, 362, 1675-1685. [CrossRef] [PubMed]

58. Chalasani, N.; Younossi, Z.; Lavine, J.E.; Charlton, M.; Cusi, K.; Rinella, M.; Harrison, S.A.; Brunt, E.M.; Sanyal, A.J. The diagnosis and management of nonalcoholic fatty liver disease: Practice guidance from the American Association for the Study of Liver Diseases. Hepatology 2018, 67, 328-357. [CrossRef] [PubMed]

59. Armstrong, M.J.; Gaunt, P.; Aithal, G.P.; Barton, D.; Hull, D.; Parker, R.; Hazlehurst, J.M.; Guo, K.; LEAN Trial Team; Abouda, G.; et al. Liraglutide safety and efficacy in patients with non-alcoholic steatohepatitis (LEAN): A multicentre, double-blind, randomised, placebo-controlled phase 2 study. Lancet 2016, 387, 679-690. [CrossRef] 
60. Mendez-Sanchez, N.; Cruz-Ramon, V.C.; Ramirez-Perez, O.L.; Hwang, J.P.; Barranco-Fragoso, B.; Cordova-Gallardo, J. New Aspects of Lipotoxicity in Nonalcoholic Steatohepatitis. Int. J. Mol. Sci. 2018, 19, 2034. [CrossRef]

61. Zhang, H.; He, S.M.; Sun, J.; Wang, C.; Jiang, Y.F.; Gu, Q.; Feng, X.W.; Du, B.; Wang, W.; Shi, X.D.; et al. Prevalence and etiology of abnormal liver tests in an adult population in Jilin, China. Int. J. Med. Sci. 2011, 8, 254-262. [CrossRef] [PubMed]

62. Liao, X.-H.; Cao, X.; Liu, J.; Xie, X.-H.; Sun, Y.-H.; Zhong, B.-H. Prevalence and features of fatty liver detected by physical examination in Guangzhou. World J. Gastroenterol. 2013, 19, 5334-5339. [CrossRef] [PubMed]

63. Ruscica, M.; Ferri, N.; Macchi, C.; Meroni, M.; Lanti, C.; Ricci, C.; Maggioni, M.; Fracanzani, A.L.; Badiali, S.; Fargion, S.; et al. Liver fat accumulation is associated with circulating PCSK9. Ann. Med. 2016, 48, 384-391. [CrossRef] [PubMed]

64. Schult, A.; Eriksson, H.; Wallerstedt, S.; Kaczynski, J. Overweight and hypertriglyceridemia are risk factors for liver cirrhosis in middle-aged Swedish men. Scand. J. Gastroenterol. 2011, 46, 738-744. [CrossRef] [PubMed]

65. Kantartzis, K.; Rittig, K.; Cegan, A.; Machann, J.; Schick, F.; Balletshofer, B.; Fritsche, A.; Schleicher, E.; Häring, H.-U.; Stefan, N. Fatty liver is independently associated with alterations in circulating HDL2 and HDL3 subfractions. Diabetes Care 2008, 31, 366-368. [CrossRef]

66. Speliotes, E.K.; Massaro, J.M.; Hoffmann, U.; Vasan, R.S.; Meigs, J.B.; Sahani, D.V.; Hirschhorn, J.N.; O'Donnell, C.J.; Fox, C.S. Fatty liver is associated with dyslipidemia and dysglycemia independent of visceral fat: The Framingham Heart Study. Hepatology 2010, 51, 1979-1987. [CrossRef] [PubMed]

67. Kamal, S.; Khan, M.A.; Seth, A.; Cholankeril, G.; Gupta, D.; Singh, U.; Kamal, F.; Howden, C.W.; Stave, C.; Nair, S.; et al. Beneficial Effects of Statins on the Rates of Hepatic Fibrosis, Hepatic Decompensation, and Mortality in Chronic Liver Disease: A Systematic Review and Meta-Analysis. Am. J. Gastroenterol. 2017, 112, 1495-1505. [CrossRef] [PubMed]

68. Kim, G.; Jang, S.-Y.; Nam, C.M.; Kang, E.S. Statin use and the risk of hepatocellular carcinoma in patients at high risk: A nationwide nested case-control study. J. Hepatol. 2018, 68, 476-484. [CrossRef]

69. Pastori, D.; Polimeni, L.; Baratta, F.; Pani, A.; Del Ben, M.; Angelico, F. The efficacy and safety of statins for the treatment of non-alcoholic fatty liver disease. Dig. Liver Dis. 2015, 47, 4-11. [CrossRef]

70. Athyros, V.G.; Alexandrides, T.K.; Bilianou, H.; Cholongitas, E.; Doumas, M.; Ganotakis, E.S.; Goudevenos, J.; Elisaf, M.S.; Germanidis, G.; Giouleme, O.; et al. The use of statins alone, or in combination with pioglitazone and other drugs, for the treatment of non-alcoholic fatty liver disease/non-alcoholic steatohepatitis and related cardiovascular risk. An Expert Panel Statement. Metab. Clin. Exp. 2017, 71, 17-32. [CrossRef]

71. Wigg, A.J.; Roberts-Thomson, I.C.; Dymock, R.B.; McCarthy, P.J.; Grose, R.H.; Cummins, A.G. The role of small intestinal bacterial overgrowth, intestinal permeability, endotoxaemia, and tumour necrosis factor alpha in the pathogenesis of non-alcoholic steatohepatitis. Gut 2001, 48, 206-211. [CrossRef] [PubMed]

72. Abdel-Razik, A.; Mousa, N.; Shabana, W.; Refaey, M.; Elzehery, R.; Elhelaly, R.; Zalata, K.; Abdelsalam, M.; Eldeeb, A.A.; Awad, M.; et al. Rifaximin in nonalcoholic fatty liver disease: Hit multiple targets with a single shot. Eur. J. Gastroenterol. Hepatol. 2018, 30, 1237-1246. [CrossRef] [PubMed]

73. Borrelli, A.; Bonelli, P.; Tuccillo, F.M.; Goldfine, I.D.; Evans, J.L.; Buonaguro, F.M.; Mancini, A. Role of gut microbiota and oxidative stress in the progression of non-alcoholic fatty liver disease to hepatocarcinoma: Current and innovative therapeutic approaches. Redox Biol. 2018, 15, 467-479. [CrossRef] [PubMed]

74. Fritz, R.; Bol, J.; Hebling, U.; Angermüller, S.; Völkl, A.; Fahimi, H.D.; Mueller, S. Compartment-dependent management of $\mathrm{H}(2) \mathrm{O}(2)$ by peroxisomes. Free Radic. Biol. Med. 2007, 42, 1119-1129. [CrossRef] [PubMed]

75. Ryoo, J.-H.; Suh, Y.J.; Shin, H.C.; Cho, Y.K.; Choi, J.-M.; Park, S.K. Clinical association between non-alcoholic fatty liver disease and the development of hypertension. J. Gastroenterol. Hepatol. 2014, 29, 1926-1931. [CrossRef] [PubMed]

76. Alwahsh, S.M.; Gebhardt, R. Dietary fructose as a risk factor for non-alcoholic fatty liver disease (NAFLD). Arch. Toxicol. 2017, 91, 1545-1563. [CrossRef] [PubMed]

77. Abdelmalek, M.F.; Suzuki, A.; Guy, C.; Unalp-Arida, A.; Colvin, R.; Johnson, R.J.; Diehl, A.M.; Nonalcoholic Steatohepatitis Clinical Research Network. Increased fructose consumption is associated with fibrosis severity in patients with nonalcoholic fatty liver disease. Hepatology 2010, 51, 1961-1971. [CrossRef]

78. Cusi, K. Nonalcoholic fatty liver disease in type 2 diabetes mellitus. Curr. Opin. Endocrinol. Diabetes Obes. 2009, 16, 141-149. [CrossRef] 
79. Bray, G.A.; Popkin, B.M. Calorie-sweetened beverages and fructose: What have we learned 10 years later. Pediatr. Obes. 2013, 8, 242-248. [CrossRef]

80. Lu, W.; Li, S.; Li, J.; Wang, J.; Zhang, R.; Zhou, Y.; Yin, Q.; Zheng, Y.; Wang, F.; Xia, Y.; et al. Effects of Omega-3 Fatty Acid in Nonalcoholic Fatty Liver Disease: A Meta-Analysis. Gastroenterol. Res. Pract. 2016, 2016, 1459790. [CrossRef]

81. Baratta, F.; Pastori, D.; Polimeni, L.; Bucci, T.; Ceci, F.; Calabrese, C.; Ernesti, I.; Pannitteri, G.; Violi, F.; Angelico, F.; et al. Adherence to Mediterranean Diet and Non-Alcoholic Fatty Liver Disease: Effect on Insulin Resistance. Am. J. Gastroenterol. 2017, 112, 1832-1839. [CrossRef] [PubMed]

82. Abenavoli, L.; Di Renzo, L.; Boccuto, L.; Alwardat, N.; Gratteri, S.; De Lorenzo, A. Health benefits of Mediterranean diet in nonalcoholic fatty liver disease. Expert Rev. Gastroenterol. Hepatol. 2018, 12, 873-881. [CrossRef]

83. Anania, C.; Perla, F.M.; Olivero, F.; Pacifico, L.; Chiesa, C. Mediterranean diet and nonalcoholic fatty liver disease. World J. Gastroenterol. 2018, 24, 2083-2094. [CrossRef] [PubMed]

84. Kleiner, D.E.; Brunt, E.M.; Van Natta, M.; Behling, C.; Contos, M.J.; Cummings, O.W.; Ferrell, L.D.; Liu, Y.-C.; Torbenson, M.S.; Unalp-Arida, A.; et al. Nonalcoholic Steatohepatitis Clinical Research Network Design and validation of a histological scoring system for nonalcoholic fatty liver disease. Hepatology 2005, 41, 1313-1321. [CrossRef]

85. Juluri, R.; Vuppalanchi, R.; Olson, J.; Unalp, A.; Van Natta, M.L.; Cummings, O.W.; Tonascia, J.; Chalasani, N. Generalizability of the nonalcoholic steatohepatitis Clinical Research Network histologic scoring system for nonalcoholic fatty liver disease. J. Clin. Gastroenterol. 2011, 45, 55-58. [CrossRef] [PubMed]

86. Verma, S.; Jensen, D.; Hart, J.; Mohanty, S.R. Predictive value of ALT levels for non-alcoholic steatohepatitis (NASH) and advanced fibrosis in non-alcoholic fatty liver disease (NAFLD). Liver Int. 2013, 33, 1398-1405. [CrossRef]

87. Feldstein, A.E.; Wieckowska, A.; Lopez, A.R.; Liu, Y.-C.; Zein, N.N.; McCullough, A.J. Cytokeratin-18 fragment levels as noninvasive biomarkers for nonalcoholic steatohepatitis: A multicenter validation study. Hepatology 2009, 50, 1072-1078. [CrossRef] [PubMed]

88. Lin, Z.-H.; Xin, Y.-N.; Dong, Q.-J.; Wang, Q.; Jiang, X.-J.; Zhan, S.-H.; Sun, Y.; Xuan, S.-Y. Performance of the aspartate aminotransferase-to-platelet ratio index for the staging of hepatitis C-related fibrosis: An updated meta-analysis. Hepatology 2011, 53, 726-736. [CrossRef] [PubMed]

89. Rinella, M.E.; Loomba, R.; Caldwell, S.H.; Kowdley, K.; Charlton, M.; Tetri, B.; Harrison, S.A. Controversies in the Diagnosis and Management of NAFLD and NASH. Gastroenterol. Hepatol. 2014, 10, $219-227$.

90. Angulo, P.; Bugianesi, E.; Bjornsson, E.S.; Charatcharoenwitthaya, P.; Mills, P.R.; Barrera, F.; Haflidadottir, S.; Day, C.P.; George, J. Simple noninvasive systems predict long-term outcomes of patients with nonalcoholic fatty liver disease. Gastroenterology 2013, 145, 782-789. [CrossRef]

91. Shah, A.G.; Lydecker, A.; Murray, K.; Tetri, B.N.; Contos, M.J.; Sanyal, A.J. Nash Clinical Research Network Comparison of noninvasive markers of fibrosis in patients with nonalcoholic fatty liver disease. Clin. Gastroenterol. Hepatol. 2009, 7, 1104-1112. [CrossRef]

92. Imbert-Bismut, F.; Ratziu, V.; Pieroni, L.; Charlotte, F.; Benhamou, Y.; Poynard, T.; MULTIVIRC Group. Biochemical markers of liver fibrosis in patients with hepatitis $C$ virus infection: A prospective study. Lancet 2001, 357, 1069-1075. [CrossRef]

93. Munteanu, M.; Tiniakos, D.; Anstee, Q.; Charlotte, F.; Marchesini, G.; Bugianesi, E.; Trauner, M.; Romero Gomez, M.; Oliveira, C.; Day, C.; et al. Diagnostic performance of FibroTest, SteatoTest and ActiTest in patients with NAFLD using the SAF score as histological reference. Aliment. Pharmacol. Ther. 2016, 44, 877-889. [CrossRef] [PubMed]

94. Halfon, P.; Imbert-Bismut, F.; Messous, D.; Antoniotti, G.; Benchetrit, D.; Cart-Lamy, P.; Delaporte, G.; Doutheau, D.; Klump, T.; Sala, M.; et al. A prospective assessment of the inter-laboratory variability of biochemical markers of fibrosis (FibroTest) and activity (ActiTest) in patients with chronic liver disease. Comp. Hepatol. 2002, 1, 3. [CrossRef] [PubMed]

95. Poynard, T.; Imbert-Bismut, F.; Munteanu, M.; Messous, D.; Myers, R.P.; Thabut, D.; Ratziu, V.; Mercadier, A.; Benhamou, Y.; Hainque, B. Overview of the diagnostic value of biochemical markers of liver fibrosis (FibroTest, HCV FibroSure) and necrosis (ActiTest) in patients with chronic hepatitis C. Comp. Hepatol. 2004, 3, 8. [CrossRef] 
96. Rosenberg, W.M.C.; Voelker, M.; Thiel, R.; Becka, M.; Burt, A.; Schuppan, D.; Hubscher, S.; Roskams, T.; Pinzani, M.; Arthur, M.J.P. European Liver Fibrosis Group Serum markers detect the presence of liver fibrosis: A cohort study. Gastroenterology 2004, 127, 1704-1713. [CrossRef] [PubMed]

97. Guajardo-Salinas, G.E.; Hilmy, A. Prevalence of nonalcoholic fatty liver disease (NAFLD) and utility of FIBROspect II to detect liver fibrosis in morbidly obese Hispano-American patients undergoing gastric bypass. Obes. Surg. 2010, 20, 1647-1653. [CrossRef] [PubMed]

98. Hernaez, R.; Lazo, M.; Bonekamp, S.; Kamel, I.; Brancati, F.L.; Guallar, E.; Clark, J.M. Diagnostic accuracy and reliability of ultrasonography for the detection of fatty liver: A meta-analysis. Hepatology 2011, 54, 1082-1090. [CrossRef]

99. Schwenzer, N.F.; Springer, F.; Schraml, C.; Stefan, N.; Machann, J.; Schick, F. Non-invasive assessment and quantification of liver steatosis by ultrasound, computed tomography and magnetic resonance. J. Hepatol. 2009, 51, 433-445. [CrossRef] [PubMed]

100. Le, Y.; Kroeker, R.; Kipfer, H.D.; Lin, C. Development and evaluation of twist dixon for dynamic contrast-enhanced (dce) mri with improved acquisition efficiency and fat suppression. J. Magn. Reson. Imaging 2012, 36, 483-491. [CrossRef] [PubMed]

101. Noureddin, M.; Lam, J.; Peterson, M.R.; Middleton, M.; Hamilton, G.; Le, T.A.; Bettencourt, R.; Changchien, C.; Brenner, D.A.; Sirlin, C.; et al. Utility of magnetic resonance imaging versus histology for quantifying changes in liver fat in nonalcoholic fatty liver disease trials. Hepatology 2013, 58, 1930-1940. [CrossRef] [PubMed]

102. Boursier, J.; Vergniol, J.; Guillet, A.; Hiriart, J.-B.; Lannes, A.; Le Bail, B.; Michalak, S.; Chermak, F.; Bertrais, S.; Foucher, J.; et al. Diagnostic accuracy and prognostic significance of blood fibrosis tests and liver stiffness measurement by FibroScan in non-alcoholic fatty liver disease. J. Hepatol. 2016, 65, 570-578. [CrossRef]

103. Dulai, P.S.; Sirlin, C.B.; Loomba, R. MRI and MRE for non-invasive quantitative assessment of hepatic steatosis and fibrosis in NAFLD and NASH: Clinical trials to clinical practice. J. Hepatol. 2016, 65, 1006-1016. [CrossRef] [PubMed]

104. Chen, J.; Yin, M.; Talwalkar, J.A.; Oudry, J.; Glaser, K.J.; Smyrk, T.C.; Miette, V.; Sandrin, L.; Ehman, R.L. Diagnostic Performance of MR Elastography and Vibration-controlled Transient Elastography in the Detection of Hepatic Fibrosis in Patients with Severe to Morbid Obesity. Radiology 2017, 283, 418-428. [CrossRef] [PubMed]

105. Imajo, K.; Kessoku, T.; Honda, Y.; Tomeno, W.; Ogawa, Y.; Mawatari, H.; Fujita, K.; Yoneda, M.; Taguri, M.; Hyogo, H.; et al. Magnetic Resonance Imaging More Accurately Classifies Steatosis and Fibrosis in Patients With Nonalcoholic Fatty Liver Disease Than Transient Elastography. Gastroenterology 2016, 150, 626-637. [CrossRef]

106. Ferraioli, G.; Tinelli, C.; Dal Bello, B.; Zicchetti, M.; Filice, G.; Filice, C. Liver Fibrosis Study Group Accuracy of real-time shear wave elastography for assessing liver fibrosis in chronic hepatitis C: A pilot study. Hepatology 2012, 56, 2125-2133. [CrossRef]

107. Chen, J.; Talwalkar, J.A.; Yin, M.; Glaser, K.J.; Sanderson, S.O.; Ehman, R.L. Early detection of nonalcoholic steatohepatitis in patients with nonalcoholic fatty liver disease by using MR elastography. Radiology 2011, 259, 749-756. [CrossRef]

(C) 2019 by the authors. Licensee MDPI, Basel, Switzerland. This article is an open access article distributed under the terms and conditions of the Creative Commons Attribution (CC BY) license (http://creativecommons.org/licenses/by/4.0/). 